\title{
Anti-inflammatory and anti-proliferative effect of herbal medicines (APR) in RAW264.7 cells
}

\author{
HAN-SEOK CHOI, HYE SOOK SEO, SOON RE KIM, \\ YOUN KYUNG CHOI, YONG-CHEOL SHIN and SEONG-GYU KO
}

\begin{abstract}
Laboratory of Clinical Biology and Pharmacogenomics and Center for Clinical Research and Genomics, Institute of Oriental Medicine, Kyung Hee University, Seoul 130-701, Republic of Korea
\end{abstract}

Received August 13, 2013; Accepted February 24, 2014

DOI: $10.3892 / \mathrm{mmr} .2014 .2033$

\begin{abstract}
The objective of the present study was to analyze the effect of a mixture of medicinal plants [Angelica gigas Nakai, Panax ginseng and Rhus verniciflua Stokes (APR)] on lipopolysaccharide (LPS)-induced inflammatory responses in the murine macrophage cell line RAW264.7. Cells were treated with APR and LPS at various concentrations and indicated times. WST assay, trypan blue assay and quantification of activated cells demonstrated that APR suppressed cell proliferation in a dose-dependent manner. APR induced G1 cell cycle arrest and inhibited the LPS-induced phosphorylation of protein kinase B (AKT), extracellular signal-regulated kinase (ERK), mitogen-activated protein kinase (p38) and necrosis factor $\kappa \mathrm{B}(\mathrm{NF}-\kappa \mathrm{B})$. APR also suppressed nitric oxide synthase isoform (iNOS) and prostaglandin endoperoxide synthase 2 (Cox-2) messenger ribonucleic acid (mRNA) expression induced by LPS. Furthermore, APR decreased LPS-induced intracellular reactive oxygen species (ROS) levels, mitochondrial membrane potential, as well as induced PARP and caspase-3 cleavage, suggesting that APR causes apoptosis. In conclusion, the present study indicated that APR may be advantageous in treating inflammatory disease.
\end{abstract}

\section{Introduction}

Inflammatory response is a major defense mechanism against pathogens and chemical or mechanical injury. These phenomena are mediated by inflammatory cells including macrophages. Activated macrophages produce reactive oxygen species (ROS)

Correspondence to: Dr Seong-Gyu Ko, Laboratory of Clinical Biology and Pharmacogenomics and Center for Clinical Research and Genomics, Institute of Oriental Medicine, Kyunghee University, 26 Kyungheedae-ro, Dongdaemun-gu, Seoul 130-701, Republic of Korea E-mail: epiko@khu.ac.kr

Key words: Angelica gigas Nakai, Panax ginseng, Rhus verniciflua Stokes, inflammation, RAW264.7, lipopolysaccharide, reactive oxygen species and nitric oxide (NO), and cause substantial oxidant injury to surrounding tissue (1-3). Extensive laboratory and clinical evidence indicates that chronic inflammation contributes to cancer (4). Oxidative stress-induced neuron injury induces a variety of neurodegenerative diseases including Alzheimer's and Parkinson's disease as well as cerebral ischemia (5).

The dried roots of Angelica gigas Nakai (AGN) have been traditionally used in Oriental Medicine. It is known in Korean as 'Cham-dang-gui'. Several coumarin derivatives and a pectic polysaccharide were isolated from AGN (6). These derivatives are known to inhibit cancer cell adhesion and invasion (7), have anti-diabetic activity (8), suppress androgen-induced and -independent cell proliferation, and cause anti-inflammatory activities (9) and neuroprotective activity (10).

Panax ginseng (PG), one of the most well-known herbal medicines, has been commonly used in East Asia. Total saponins and ginsenosides are the major active components of PG (11). Ginseng has various biological activities, including inhibition of tumor-induced angiogenesis, prevention of tumor invasion and metastasis (12), as well as anti-infective (13), anti-diabetic (14), anti-inflammatory (15), and neuroprotective activities (16).

Rhus verniciflua Stokes (RVS) has traditionally been used as an ingredient in East Asian Medicine for the treatment of gastritis, stomach cancer and atherosclerosis. The compounds identified from RVS are as follows: Gallic acid, protocatechuic acid, quercetin, fustin, fisetin, sulfuretin and butein (17). RVS protects from oxidative damage by scavenging reactive oxygen species (ROS) (18) and it has anti-proliferative, anti-cancer and anti-inflammatory effects (19).

In the present study, the effect of a mixture of three medicinal plants AGN, PG, RVS (APR) on lipopolysaccharide (LPS)induced inflammatory responses in the mouse macrophage cell line RAW264.7 was evaluated. It was assessed whether an ethanolic (EtOH) extract of APR suppresses LPS-induced inflammatory responses in RAW264.7. The present study also investigated whether APR exhibits anti-proliferative activity regulating intracellular molecules associated with cell survival and apoptosis.

\section{Materials and methods}

Cell culture. RAW264.7 mouse macrophage cells were obtained from the Korea Cell Line Bank (Seoul, Korea). 
Cells were cultured in Dulbecco's modified Eagle's medium (DMEM) supplemented with 10\% heat-inactivated fetal bovine serum (FBS) and $1 \%$ antibiotics (penicillin-streptomycin) at $37^{\circ} \mathrm{C}$ in a $5 \% \mathrm{CO}_{2}$ humidified incubator.

Extraction of medicinal plants (APR). Medicinal plants used in the present study were purchased from Omniherb (Daekoo, Gyeongsangbuk-do, Korea). The powder with a mass of $100 \mathrm{~g}$ (AGN and PG, root and RVS, bark) was extracted twice with 80\% (v/v) ethanol (Duksan Pharmaceutical Co., Ltd., Ansan, Republic of Korea) by using an Ultra-sonicator (Branson, Danbury, CT, USA) for $30 \mathrm{~min}$ at room temperature. The alcoholic extract was filtered through a $0.22 \mu \mathrm{m}$ filter, the solvent was evaporated at $40^{\circ} \mathrm{C}$ and the residue freeze-dried. The yields of the extracts were 38.2, 26.4 and $13.7 \%(\mathrm{w} / \mathrm{w})$ for AGN, PG and RVS, respectively. The plant extract mixture was prepared as AGN $: \mathrm{PG}: \mathrm{RVS}=1: 1: 0.1$.

Cell proliferation assay. The cell proliferation rate was determined using the water soluble tetrazolium (WST) assay following treatment with APR. The WST assay is based on the cleavage of the yellow tetrazolium salt to purple formazan crystals by metabolically active live cells.

RAW264.7 cells ( $1 \times 10^{4}$ cells/well) were seeded in 96-well plates, incubated overnight and treated with APR. Following $24 \mathrm{~h}$ of incubation, $10 \mu \mathrm{l}$ WST solution was added to $100 \mu \mathrm{l}$ cell culture medium and the plates were incubated for a further $2 \mathrm{~h}$. The optical density was determined at $490 \mathrm{~nm}$ using an ELISA reader (Molecular Devices, Palo Alto, CA, USA).

Cell death assay. Cell death following APR treatment was determined using the trypan blue assay. Trypan blue selectively stains dead cells. RAW264.7 cells were treated with APR for 12 and $24 \mathrm{~h}$, respectively. The cells were then suspended and stained with trypan blue solution (Sigma Aldrich; St. Louis, MO, USA). The cell number was determined by counting using a hemocytometer.

Cell surface observation. Cells were seeded into $60-\mathrm{mm}$ culture dishes at a density of $3 \times 10^{5}$ cells/dish. The following day, the cells were treated with APR for $12 \mathrm{~h}$. The cell surface was observed by capturing an image using a camera (Olympus) attached to a microscope.

Mitochondrial membrane potential analysis. The loss of mitochondrial membrane potential is a specific characteristic of apoptosis. 5,5',6,6'-Tetrachloro-1,1',3,3'-tetraethylbenzimid azolylcarbocyanine iodide (JC-1) is a membrane-permeable dye widely used for determining the mitochondrial membrane potential using flow cytometry and fluorescent microscopy. Cells were seeded into $60 \mathrm{~mm}$ culture dishes at a density of $3 \times 10^{5}$ cells/dish. The following day, the cells were treated with APR for $24 \mathrm{~h}$. Cells were harvested from each culture dish, washed with phosphate-buffered saline (PBS), suspended in PBS containing $2 \mu \mathrm{M} \mathrm{JC}-1$ and incubated for $30 \mathrm{~min}$ at $37^{\circ} \mathrm{C}$ in the dark. The data were analyzed by FACSCalibur flow cytometry (BD Biosciences, Franklin Lakes, NJ, USA).

Assessment of intracellular reactive oxygen species (ROS) levels. The molecule 2',7'-dichlorofluorescein diacetate (DCFH-DA) freely permeates cells, and following incorporation into cells, is converted into the fluorescent 2,7-dichlorofluorescein (DCF) by oxidative substances, revealing the intracellular production of redox-active substances. It has been widely used to investigate oxidative damage in intact cells. Cells were seeded into $35 \mathrm{~mm}$ culture dishes containing glass coverslips. Following different pretreatments, the cells were washed with PBS and incubated with $20 \mu \mathrm{M} \mathrm{DCFH}-\mathrm{DA}$ for $30 \mathrm{~min}$ at $37^{\circ} \mathrm{C}$ in the dark. Following washing with cold PBS, the fluorescence was captured using a laser confocal scanning microscope (LSM 510; Carl Zeiss, Jena, Germany) and a FACSCalibur flow cytometer (BD Biosciences, San Jose, CA, USA). DCF fluorescence was measured at an excitation wavelength of $488 \mathrm{~nm}$ and emission at 515-540 nm.

RNA extraction and reverse transcription polymerase chain reaction (RT-PCR). Cells were collected by centrifugation and RNA was extracted using an Invitrogen kit (Grand Island, NY, USA), according to the manufacturer's instructions. Primers were designed for RT-PCR for nitric oxide synthase isoform (iNOS) and prostaglandin endoperoxide synthase 2 (Cox-2). The primer sequences were as follows: (sense) 5'-GGA GAGACTATCAAGATAGT-3' and (antisense) 5'-ATGGTC AGTAGACTTTTACA-3' for COX-2; (sense) 5'-AATGGCAAC ATCAGGTCGGCCATCACT-3' and (antisense) 5'-GCT GTGTGTCACAGAAGTCTCGAACTC-3' for iNOS; (sense) 5'-GAGGGGCCATCCACAGTCTTC-3' and (antisense) 5'-CATCACCATCTTCCAGGAGCG-3' for glyceraldehyde 3 -phosphate dehydrogenase (GAPDH). The sequencing involved 30 cycles with denaturation at $94^{\circ} \mathrm{C}$ for $45 \mathrm{sec}$, annealing at $55^{\circ} \mathrm{C}$ for $45 \mathrm{sec}$ and extension at $72^{\circ} \mathrm{C}$ for $45 \mathrm{sec}$. The resulting PCR products were resolved on $1 \%$ agarose gels containing ethidium bromide.

Western blot analysis. Whole cell lysates from cells treated with DMSO and APR in the presence or absence of LPS were prepared by washing with ice-cold PBS and lysis with a radioimmunoprecipitation assay (RIPA) buffer. Equal amounts of protein $(30 \mu \mathrm{g})$ from the cell lysates were boiled for $5 \mathrm{~min}$ in SDS-PAGE sample buffer, resolved by $10 \%$ SDS-PAGE, transferred to nitrocellulose membranes at $80 \mathrm{~V}$ for $1.5 \mathrm{~h}$ and visualized using western blot analysis and chemiluminescence.

\section{Results}

Effects of APR on cell viability. The anti-proliferative effects of APR were assessed on RAW264.7 mouse macrophage cells. First, the inhibitory effect of APR on cell proliferation was investigated using the WST assay (Fig. 1a). For this purpose, the cells were treated with APR at concentrations of $0-1,000 \mu \mathrm{g} / \mathrm{ml}$ and $1 \mu \mathrm{g} / \mathrm{ml}$ LPS for $12 \mathrm{~h}$. LPS alone did not show any proliferative activity in RAW264.7 cells. However, APR significantly inhibited cell proliferation at concentrations of $250-1,000 \mu \mathrm{g} / \mathrm{ml}$, suggesting that APR inhibits the growth of RAW264.7 cells. Second, the cell death rate was determined using the trypan blue assay during APR treatment (Fig. 1b). At $24 \mathrm{~h}$ of incubation, APR significantly decreased the percentage of surviving cells.

Changes in the cellular morphology under LPS and APR treatment were also observed (Fig. 1c). Untreated RAW264.7 cells are circular shaped. However, following incubation with LPS, the cells exerted an anomalous shape and 


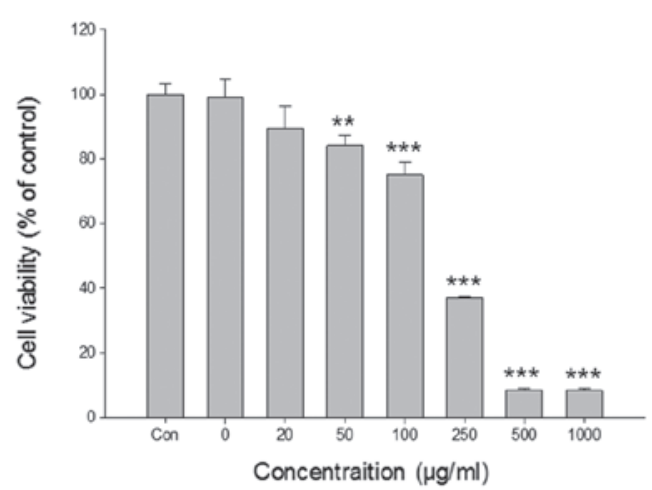

C

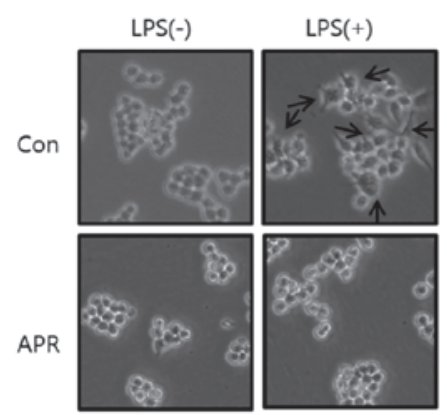

B
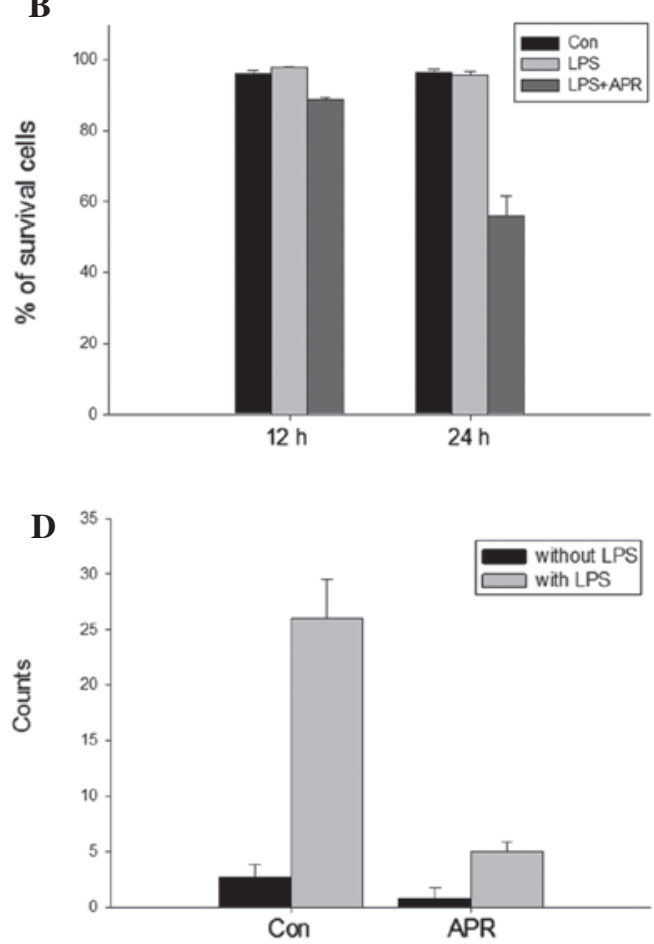

Figure 1. Effect of APR on proliferation and death of RAW264.7 cells. (A) Cell proliferation rate was determined using the WST assay. RAW264.7 cells were treated with APR at concentrations of $0-1,000 \mu \mathrm{g} / \mathrm{ml}$ in the absence or presence of $1 \mu \mathrm{g} / \mathrm{ml}$ LPS for $24 \mathrm{~h}$. APR significantly inhibited cell proliferation at concentrations of $250-1,000 \mu \mathrm{g} / \mathrm{ml}$. Each value is the mean \pm standard deviation $\left({ }^{* * *} \mathrm{P}<0.01 ;{ }^{* * * *} \mathrm{P}<0.001\right.$ according to the Student's t-test). (B) The cell death rate was determined using trypan blue assay. RAW264.7 cells were treated with $150 \mu \mathrm{g} / \mathrm{ml}$ APR in the absence or presence of $1 \mu \mathrm{g} / \mathrm{ml} \mathrm{LPS} \mathrm{for} 12 \mathrm{and} 24 \mathrm{~h}$, respectively. APR caused cell death in a time-dependent manner. (C) LPS-induced morphological changes were reversed by APR in RAW264.7 cells. Cells were treated with APR in the absence or presence of $1 \mu \mathrm{g} / \mathrm{ml}$ LPS for $12 \mathrm{~h}$. APR inhibited the activation of RAW264.7 cells induced by LPS. (D) Number of cell surface changes in RAW264.7 cells. Cells were treated with APR in the absence or presence of $1 \mu \mathrm{g} / \mathrm{ml} \mathrm{LPS} \mathrm{for} 12 \mathrm{~h}$. The cell surface was observed on an image captured by a camera attached to a microscope. APR, Angelica gigas Nakai, Panax ginseng and Rhus verniciflua Stokes; LPS, liposaccharide.

A

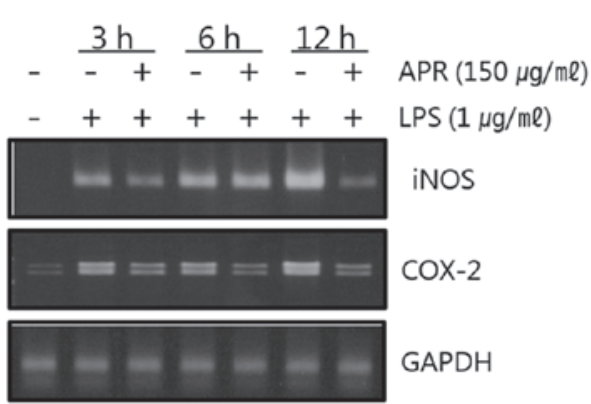

B
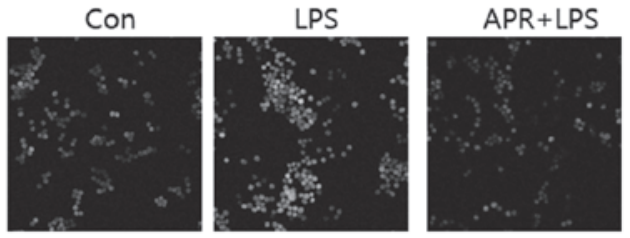

C

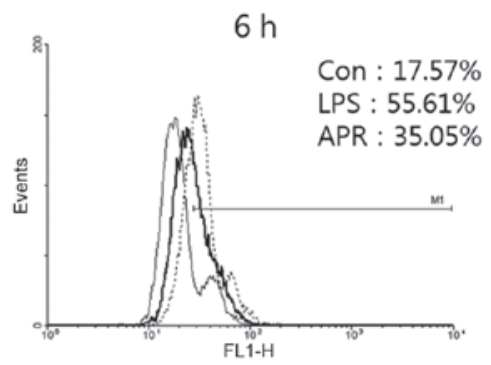

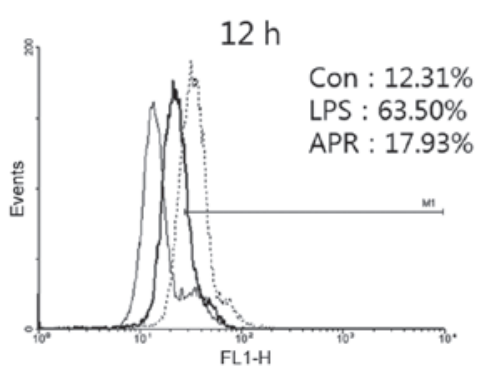

Figure 2. APR decreased iNOS and Cox-2 mRNA expression and suppressed intracellular ROS levels induced by LPS in RAW264.7 cells. (A) The expression of iNOS and COX-2 mRNA was assayed by RT-PCR. Cells were treated with $150 \mu \mathrm{g} / \mathrm{ml}$ APR in the absence or presence of $1 \mu \mathrm{g} / \mathrm{ml} \mathrm{LPS}$ for $12 \mathrm{~h}$. APR suppressed iNOS and COX-2 mRNA expression induced by LPS. ROS were detected by (B) laser confocal scanning microscopy and (C) flow cytometry with DCFH-DA. Cells were treated with $150 \mu \mathrm{g} / \mathrm{ml}$ APR in the absence or presence of $1 \mu \mathrm{g} / \mathrm{ml}$ LPS for $6 \mathrm{~h}$ and incubated with DCFH-DA for $30 \mathrm{~min}$. DCF fluorescence was measured using a confocal laser-scanning microscopy and FACSCalibur. APR inhibited ROS generation induced by LPS. APR, Angelica gigas Nakai, Panax ginseng and Rhus verniciflua Stokes; iNOS, nitric oxide synthase isoform; Cox-2, prostaglandin endoperoxide synthase 2; ROS, reactive oxygen species; LPS, liposaccharide RT-PCR, reverse transcription polymerase chain reaction; DCFH-DA, 2',7'-dichlorofluorescein diacetate; GADPH, glyceraldehyde 3-phosphate dehydrogenase. 

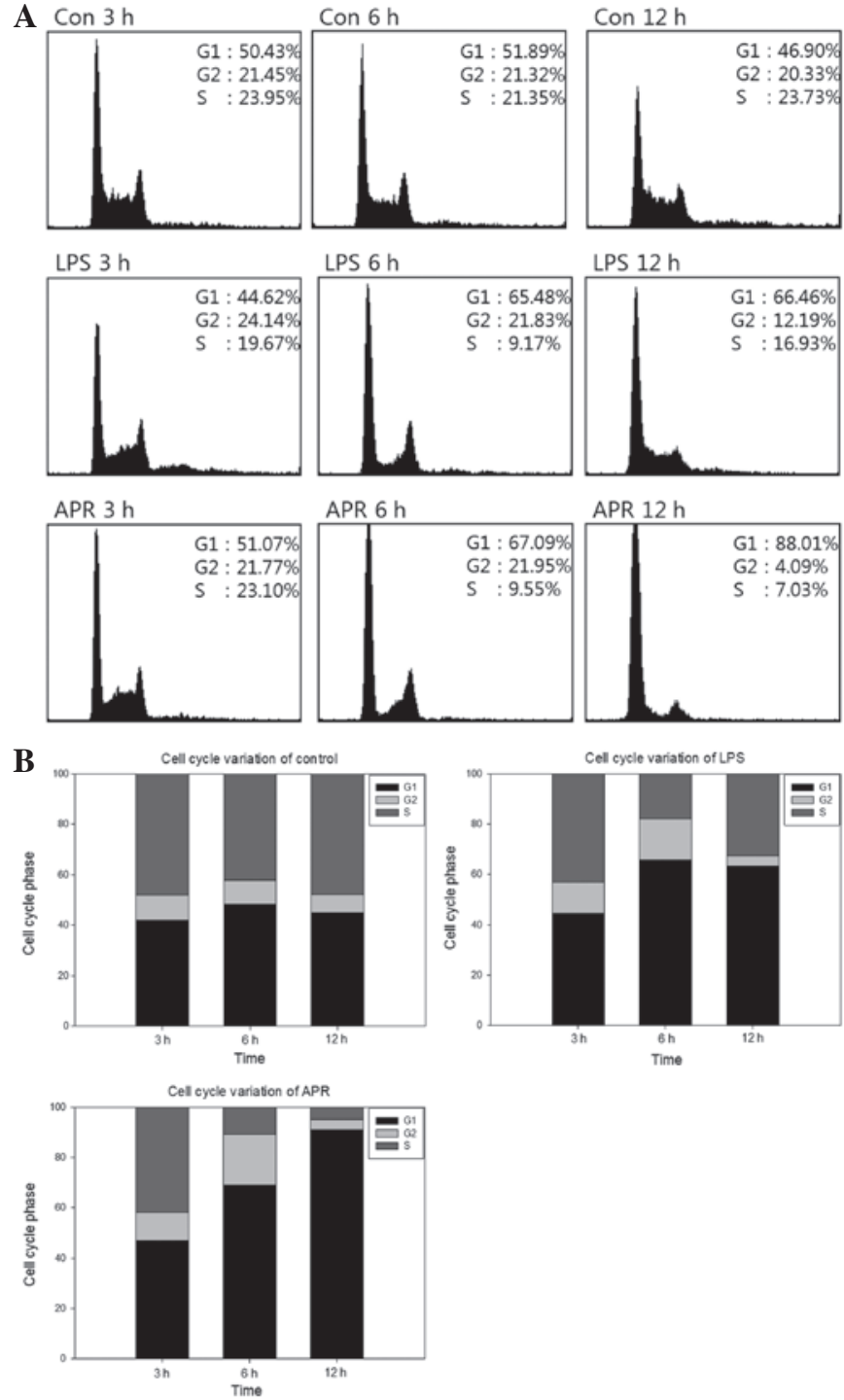

C

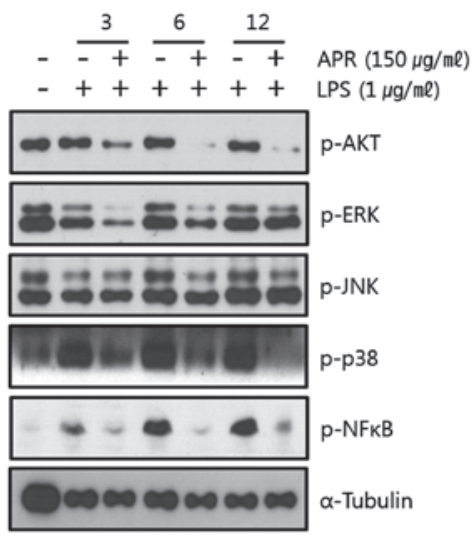

Figure 3. APR affects cell cycle. (A) Cell cycle was analyzed using FACS Cells were treated with APR $(150 \mu \mathrm{g} / \mathrm{ml})$ in the absence or presence of $1 \mu \mathrm{g} /$ $\mathrm{ml}$ LPS for 3, 6 and $12 \mathrm{~h}$, respectively. Cells were stained with propidium iodide solution and analyzed by flow cytometry. APR caused G1 arrest (B) G1, S and G2/M phase fractions were quantified from DNA histograms data in A. (C) Effect of APR on the expression of intracellular molecules in RAW264.7 cells. Cells were treated with APR $(150 \mu \mathrm{g} / \mathrm{ml})$ in the absence or presence of $1 \mu \mathrm{g} / \mathrm{ml}$ LPS for 3, 6 and $12 \mathrm{~h}$, respectively. Cell extracts were subjected to western blot analysis with specific antibodies. APR had inhibitory effects on AKT, ERK, p38 and NF-kB phosphorylation. APR, Angelica gigas Nakai, Panax ginseng and Rhus verniciflua Stokes; FACS, fluorescence-activated cell sorting; LPS, liposaccharide; AKT, protein kinase B; ERK, extracellular signal-regulated kinase; p-JNK, c-Jun terminal kinase; p38, p38 mitogen-activated protein kinase; NF- $\kappa B$, necrosis factor $\kappa B$.
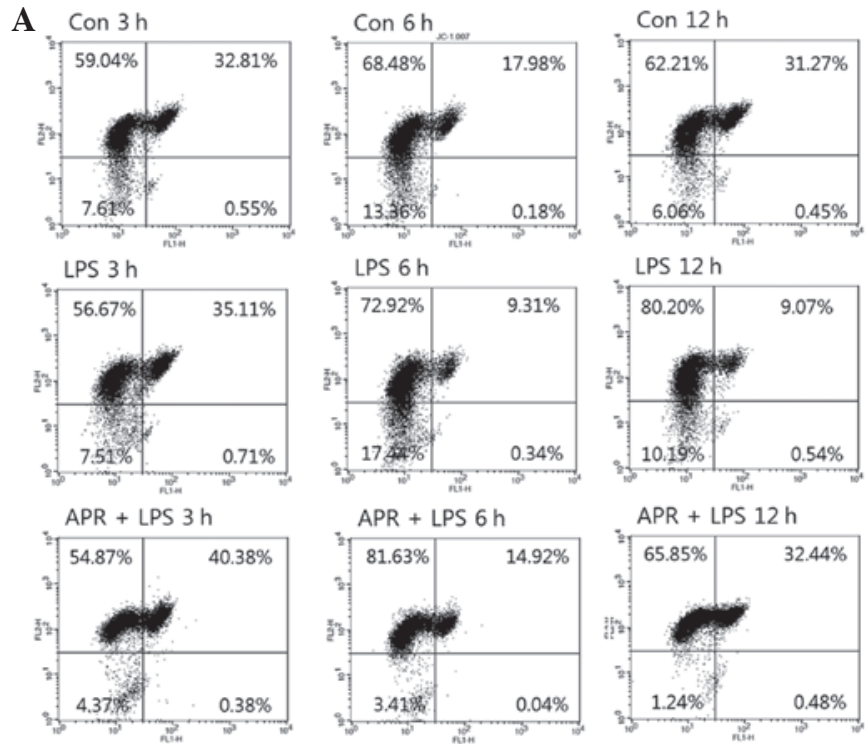

B

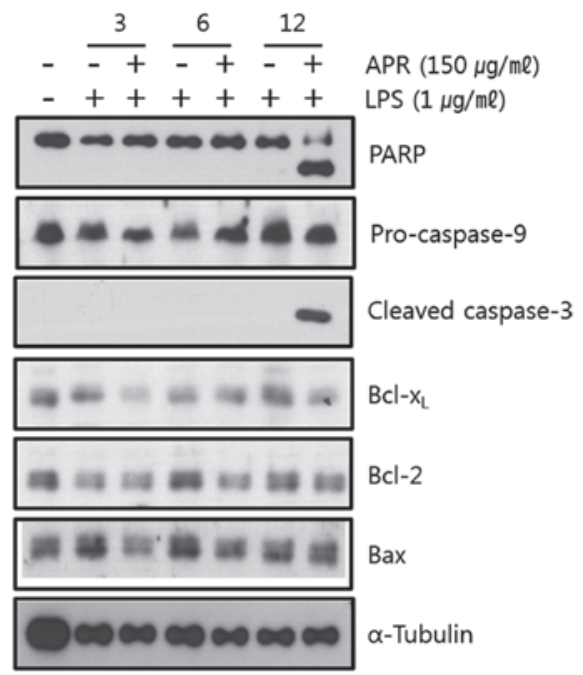

Figure 4. APR induces apoptosis through mitochondrial death pathway. (a) Cells were treated with APR $(150 \mu \mathrm{g} / \mathrm{ml})$ in the absence or presence of $1 \mu \mathrm{g} / \mathrm{ml}$ LPS for 3, 6 and $12 \mathrm{~h}$, respectively. Following incubation with JC-1, cells were analyzed by FACS. APR decreased the mitochondrial membrane potential. (b) Effect of APR on caspase activity and apoptosis in RAW264.7 cells. Cells were treated with APR $(150 \mu \mathrm{g} / \mathrm{ml})$ in the absence or presence of $1 \mu \mathrm{g} / \mathrm{ml} \mathrm{LPS}$ for 3, 6 and $12 \mathrm{~h}$, respectively. Cell extracts were subjected to western blot analysis with specific antibodies. APR cleaved PARP and caspase-3. APR, Angelica gigas Nakai, Panax ginseng and Rhus verniciflua Stokes; LPS, liposaccharide; JC-1, 5,5',6,6'-tetrachloro-1,1',3,3'-tetraethylbenzimidazolylcarbocyanine iodide; FACS, fluorescence-activated cell sorting; PARP, poly adenosine diphosphate ribose polymerase; $\mathrm{Bcl}-\mathrm{x}_{\mathrm{L}}$, B-cell lymphoma-extra large protein; Bcl-2, B-cell lymphoma 2; Bax, $\mathrm{BCl}$-2-associated protein $\mathrm{x}$.

became elongated. Microscopic examination of cells revealed a reversal of LPS-induced alteration in cell morphology following treatment with APR.

On the other hand, Fig. 1d shows the number of cell surface changes following LPS and/or APR treatment in RAW264.7 cells. APR significantly decreased the number of cell surface changes induced by LPS. These results suggest that APR inhibits the proliferation of RAW264.7 cells and blocks the LPS-induced activation of RAW264.7 cells. 
inflammatory reactions, the expression of iNOS mRNA and COX-2 mRNA in RAW264.7 cells was assessed. APR suppressed iNOS mRNA and COX-2 mRNA expression induced by LPS in RAW264.7 cells (Fig. 2a), suggesting that APR suppresses inflammatory reactions.

APR decreases ROS levels in RAW264.7 cells. ROS levels were measured by confocal microscopy (Fig. 2b) and fluorescence-activated cell sorting (FACS) analysis (Fig. 2c) using DCFH-DA. Following LPS treatment cellular ROS levels were increased. However, APR co-treatment inhibited ROS generation induced by LPS in a time-dependent manner.

APR affects cell cycle. The effect of APR on the cell cycle was assessed using FACS analysis. As shown in Fig. 3a and b, APR caused G1 phase arrest at 6 and $12 \mathrm{~h}$ of incubation in a time-dependent manner. Fig. $3 \mathrm{c}$ shows the expression of intracellular molecules associated with cell proliferation, assessed using western blot analysis.

$A P R$ suppresses protein kinase $B(p-A K T)$ and extracellular signal-regulated kinase ( $p$-ERK) expression induced by LPS in a time-dependent manner. c-Jun terminal kinase (JNK) phosphorylation was not suppressed by APR, but p38 mitogen-activated protein kinases (p38) phosphorylation induced by LPS was downregulated in a time-dependent manner by APR. Necrosis factor $\kappa \mathrm{B}(\mathrm{NF}-\kappa \mathrm{B})$ phosphorylation induced by LPS was inhibited by APR. These results suggest that APR inhibits cell proliferation by suppression of the phosphorylation of AKT, ERK, p38 and NF-kB.

APR induces apoptosis through the mitochondrial death pathway. The loss of mitochondrial membrane potential $(\Delta \Psi)$ is a hallmark of apoptosis. Mitochondrial permeability transition is an important step in the induction of cell apoptosis. JC-1 is able to selectively enter mitochondria and reversibly change the color from red to green as the membrane potential decreases. Thus, cells incubated with LPS and/or APR were stained with JC-1 and assessed through FACS analysis. It was found that APR decreased the mitochondrial membrane potential in RAW264.7 cells as shown in Fig. 4a. Treatment with LPS alone resulted in a more stable mitochondrial membrane potential (green fluorescence, $9.61 \%$ at $12 \mathrm{~h}$ ) compared with the control (green fluorescence, $31.72 \%$ at $12 \mathrm{~h}$ ). APR perturbed this stability induced by LPS and decreased the mitochondrial membrane potential (green fluorescence, $32.92 \%$ at $12 \mathrm{~h}$ ), suggesting that APR induces apoptosis through the mitochondrial death pathway.

It was also confirmed whether APR regulated the expression of apoptosis-associated molecules. As shown in Fig. 4b, APR induced the cleavage of poly adenosine diphosphate ribose polymerase (PARP) and caspase- 3 which are apoptotic products, confirming that APR causes apoptosis.

\section{Discussion}

The present study revealed that an ethanolic extract of APR suppressed the LPS-induced inflammatory responses in the mouse macrophage cell line RAW264.7.
Inflammation is a host's protection method against pathogens and is stimulated by diverse microbial products (20). Pro-inflammatory cytokines may aggravate the severity of multiple inflammatory diseases (21). Diverse inflammatory agents are able to activate NF- $\kappa B$. Activation of NF- $\kappa B$ induces inflammation and increases cell survival and tumor cell transformation (22). Mitogen-activated protein kinase (MAPK) pathways are also associated with inflammation. The ERK pathway is activated by inflammation (23).

APR effectively inhibited the growth stimulation and activation of RAW264.7 cells induced by LPS. APR significantly inhibited cell growth at concentrations of 250-1,000 $\mu \mathrm{g} / \mathrm{ml}$ and induced cell death at $150 \mu \mathrm{g} / \mathrm{ml}(24 \mathrm{~h})$. It was shown that APR negated the morphological changes of RAW264.7 cells induced by LPS. APR decreased intracellular ROS levels and suppressed iNOS and Cox-2 mRNA expression induced by LPS. APR decreased the mitochondrial membrane potential and cleaved caspase- 3 and PARP. This result indicates that APR inhibits inflammation and induces apoptosis through mitochondrial death pathways.

Since APR has an anti-inflammatory effect, it may be used for the treatment of inflammatory diseases, including rheumatoid arthritis and asthma (24). Transformation of a normal cell into tumor cell is closely associated with chronic inflammation (25), and accordingly, APR (AGN, PG and RVS) may be a useful compound for cancer prevention.

\section{Acknowledgements}

The present study was supported by the Traditional Korean Medicine R\&D Project, Ministry of Health \& Welfare, Republic of Korea (B110043).

\section{References}

1. Oh PS, Lee SJ and Lim KT: Glycoprotein isolated from Rhus verniciflua Stokes inhibits inflammation-related protein and nitric oxide production in LPS-stimulated RAW 264.7 cells. Biol Pharm Bull 30: 111-116, 2007.

2. Park EK, Shin YW, Lee HU, Kim SS, Lee YC, Lee BY and Kim DH: Inhibitory effect of ginsenoside Rbl and compound $\mathrm{K}$ on NO and prostaglandin E2 biosyntheses of RAW264.7 cells induced by lipopolysaccharide. Biol Pharm Bull 28: 652-656, 2005.

3. Yang JH,Suh SJ,Lu Y,Li X, Lee YK, Chang YC, Na MK, Choi JH, Kim CH, Son JK and Chang HW: Anti-inflammatory activity of ethylacetate fraction of Cliona celata. Immunopharmacol Immunotoxicol 33: 373-379, 2011.

4. Hofseth LJ and Wargovich MJ: Inflammation, cancer, and targets of ginseng. J Nutr 137 (1 Suppl): 183S-185S, 2007.

5. Liu Q, Kou JP and Yu BY: Ginsenoside Rg1 protects against hydrogen peroxide-induced cell death in PC12 cells via inhibiting $\mathrm{NF}-\kappa \mathrm{B}$ activation. Neurochem Int 58: 119-125, 2011.

6. Shin S, Jeon JH, Park D, Jang JY, Joo SS, Hwang BY, Choe SY and Kim YB: Anti-inflammatory effects of an ethanol extract of Angelica gigas in a Carrageenan-air pouch inflammation model. Exp Anim 58: 431-436, 2009.

7. Kim JY, Yoon YD, Ahn JM, Kang JS, Park SK, Lee K, Song KB, Kim HM and Han SB: Angelan isolated from Angelica gigas Nakai induces dendritic cell maturation through toll-like receptor 4. Int Immunopharmacol 7: 78-87, 2007.

8. Kim HM, Kang JS, Park SK, Lee K, Kim JY, Kim YJ, Hong JT, Kim Y and Han SB: Antidiabetic activity of angelan isolated from Angelica gigas Nakai. Arch Pharm Res 31: 1489-1496, 2008.

9. Kim WJ, Lee MY, Kim JH, Suk K and Lee WH: Decursinol angelate blocks transmigration and inflammatory activation of cancer cells through inhibition of PI3K, ERK and NF- $\kappa \mathrm{B}$ activation. Cancer Lett 296: 35-42, 2010. 
10. Shin S, Joo SS, Park D, Jeon JH, Kim TK, Kim JS, Park SK, Hwang BY and Kim YB: Ethanol extract of Angelica gigas inhibits croton oil-induced inflammation by suppressing the cyclooxygenase - prostaglandin pathway. J Vet Sci 11: 43-50, 2010.

11. Su W, Sun AJ, Xu DL, Zhang HQ, Yang L, Yuan LY, Jia JG, Zou YZ, Wu YL, Wang KQ and Ge JB: Inhibiting effects of total saponins of panax ginseng on immune maturation of dendritic cells induced by oxidized-low density lipoprotein. Cell Immunol 263: 99-104, 2010.

12. Park HJ, Han ES, Park DK, Lee C and Lee KW: An extract of Phellinus linteus grown on germinated brown rice inhibits inflammation markers in RAW264.7 macrophages by suppressing inflammatory cytokines, chemokines, and mediators and up-regulating antioxidant activity. J Med Food 13: 1468-1477, 2010.

13. Song Z, Kong KF, Wu H, Maricic N, Ramalingam B, Priestap H, Schneper L, Quirke JM, Høiby N and Mathee K: Panax ginseng has anti-infective activity against opportunistic pathogen Pseudomonas aeruginosa by inhibiting quorum sensing, a bacterial communication process critical for establishing infection. Phytomedicine 17: 1040-1046, 2010.

14. Kiefer D and Pantuso T: Panax ginseng. Am Fam Physician 68: 1539-1542, 2003.

15. Ahn JY, Choi IS, Shim JY, Yun EK, Yun YS, Jeong G and Song JY: The immunomodulator ginsan induces resistance to experimental sepsis by inhibiting Toll-like receptor-mediated inflammatory signals. Eur J Immunol 36: 37-45, 2006.

16. Cho SH, Chung KS, Choi JH, Kim DH and Lee KT: Compound K, a metabolite of ginseng saponin, induces apoptosis via caspase8-dependent pathway in HL-60 human leukemia cells. BMC Cancer 9: 449, 2009.

17. Jung CH, Jun CY, Lee S, Park CH, Cho K and Ko SG: Rhus verniciflua stokes extract: radical scavenging activities and protective effects on $\mathrm{H}_{2} \mathrm{O}_{2}$-induced cytotoxicity in macrophage RAW 264.7 cell lines. Biol Pharm Bull 29: 1603-1607, 2006.
18. Jung CH, Kim JH, Hong MH, Seog HM, Oh SH, Lee PJ, Kim GJ, Kim HM, Um JY and Ko SG: Phenolic-rich fraction from Rhus verniciflua Stokes (RVS) suppress inflammatory response via $\mathrm{NF}-\kappa \mathrm{B}$ and JNK pathway in lipopolysaccharide-induced RAW 264.7 macrophages. J Ethnopharmacol 110: 490-497, 2007.

19. Hong MH, Kim JH, Lee SY, Go HY, Shin YC, Kim SH and Ko SG: Early antiallergic inflammatory effects of Rhus verniciflua Stokes on human mast cells. Phytother Res 24: 288-294, 2010.

20. Lee HJ, Maeng K, Dang HT, Kang GJ, Ryou C, Jung JH, Kang HK, Prchal JT, Yoo ES and Yoon D: Anti-inflammatory effect of methyl dehydrojasmonate (J2) is mediated by the NF- $\mathrm{BB}$ pathway. J Mol Med (Berl) 89: 83-90, 2011.

21. Tang S, Shen XY, Huang HQ, Xu SW, Yu Y, Zhou CH, Chen SR, Le K, Wang YH, and Liu PQ: Cryptotanshinone suppressed inflammatory cytokines secretion in RAW264.7 macrophages through inhibition of the NF- $\kappa \mathrm{B}$ and MAPK signaling pathways. Inflammation 34: 111-118, 2011.

22. Reuter S, Prasad S, Phromnoi K, Ravindran J, Sung B, Yadav VR, Kannappan R, Chaturvedi MM and Aggarwal BB: Thiocolchicoside exhibits anticancer effects through downregulation of NF- $\kappa \mathrm{B}$ pathway and its regulated gene products linked to inflammation and cancer. Cancer Prev Res (Phila) 3: 1462-1472, 2010.

23. Fan J, Liu K, Zhang Z, Luo T, Xi Z, Song J and Liu B: Modified Si-Miao-San extract inhibits the release of inflammatory mediators from lipopolysaccharide-stimulated mouse macrophages. J Ethnopharmacol 129: 5-9, 2010.

24. Jeong JB and Jeong HJ: Rheosmin, a naturally occurring phenolic compound inhibits LPS-induced iNOS and COX-2 expression in RAW264.7 cells by blocking NF- $\kappa$ B activation pathway. Food Chem Toxicol 48: 2148-2153, 2010.

25. Reuter S, Gupta SC, Chaturvedi MM and Aggarwal BB: Oxidative stress, inflammation, and cancer: how are they linked? Free Radic Biol Med 49: 1603-1616, 2010. 